\title{
The Notion of "High" and commitment to excellence in contemporary Russian architecture. History and project: looking into future
}

\author{
Yuri Volchok ${ }^{1,2^{*}}$ \\ ${ }^{1}$ Scientific Research Institute of Theory and History of Architecture and Urban Planning, 111024, \\ Dushinskaya St., 9, Moscow, Russia \\ ${ }^{2}$ Moscow Institute of Architecture (State Academy), 107031, Rozhdestvenka St., 11, Moscow, Russia
}

\begin{abstract}
The article covers the issue of high-rise buildings (skyscrapers) construction in Russia as the dialogue of artistic image and intellectual idea. The study shows that the professional commitment to skyscrapers erection brings to the foreground the comprehension of magnitude of the notion of "contemporary" in terms of time. It is important from methodical point of view to return to the initial meaning of the notions that provide for adding authentic meaning to the words "suprematism", "commitment", "excellence", "new", "high", and other determinants of creativity capable of going beyond "flying geese" development pattern in architectural shaping. It is well known that V.G. Shukhov's patents of 1896 were widely used in contemporary morphology of shaping. The heritage of Russian Avant Garde of 1910-20ies serves as an inspiration from methodological point of view (it is more and more evident from foreign master's creative experience). This is why it is important to return, first of all, to comprehension of the author's version of the notion "suprematism" ascending to Malevich - meaning commitment to excellence and not the "emblem" of preferences in style. The article includes the arguments providing for the capture of the 2010ies and, especially, 2015-17ies as the years of critical changes in history. Russian masters of architecture started as equals the stage of cooperative creative work with foreign architects erecting skyscrapers.
\end{abstract}

\section{Introduction}

"The City is a vault full of architectural jewelry

- it is higher than the highest mountains in the World in its grandeur and loftier than all blossoming landscapes of the nature in its beauty".

K.S. Melnikov

${ }^{*}$ Corresponding author: yvolchok@gmail.com 
"The nature is not at all obliged to start with things simplest for our understanding"

E. Mach

This article is in memory of Alvin Toffler who died in June of the last year (19282016), and was, perhaps, the most recognized futurologist in today's world. He is the author of the key phrase that serves as a camertone for the text: "The future calls for attentive and careful attitude" $[1,2]$.

As far as the issue of the future is discussed in connection with the architecture of highrise buildings, the focus is made, of all possible levels of engagement with futurology issues, on the notion of "project". The project of "the future" is shaped as a dialogue of an art image and an intellectual idea. The emphasis should be made in this case on "maturation" of this dialogue into a latent (invisible from outside) stage of appearance of the new in shaping.

High-rise building construction has become, perhaps, the major (priority) feature of today's world predetermining the condition and the scale of global architectural trends. This is why the erection of literally every skyscraper in any point of the world cannot but be noticed. It becomes, as a rule, a global-scale event, the subject of public debate, academic discussions and a wide variety of interdisciplinary studies. Russian professional community does not neglect construction of skyscrapers. Thus, we can refer to the annual large international "Forum 100+" in Yekaterinburg, covering not only the current trends and new examples of high-rise constructions all over the world, but also serving as the platform for specific creative proposals for high-rise buildings and large complexes construction in various Russian cities and former USSR countries. The feasibility of skyscrapers erection not only in Moscow and St.-Petersburg but also in other large cities is substantiated as a resolute step towards their development.

At this point, the key issue of today comes to the foreground: How can we overcome the limitations imposed on creative efforts aimed at high-rise construction in this country by the "flying geese" development pattern?

The existing circumstances result in the need to stratify the issue comprehension into the two relatively independent sections. Beside the evident revelation and methodologically focused systematization of the trends changing one by one in the contemporary world, the attention fixes more and more on accumulated shaping regularities providing for the discussion of the mere possibility of (readiness for) independent solution, comprehensive from the creative point of view, of the issues and professional challenges resulting from the search for original concepts of high-rise construction in Russia. The readiness of the professional community for true skyscrapers construction shifts the focus to comprehension of magnitude of the notion of "contemporary". The regularities emerging in the process provide for revelation of the trends predetermining the future direction of an architect's professional creativity.

Methodologically, the implementation of these objectives in this work is performed through a gradual immersion into time depositions of architectural expertise in Russia. However, it is very important from methodological point of view to try and return to the initial meanings of the notions which have become overgrown, in impatient sequence of every-day life, with new historical details, particularities, limitations, often standing far away from "the original". As far as the focus in this article is made on high-rise construction issues: The way high-rise buildings arrange urban space and implement the notion of "the new" in shaping, it is necessary from methodological point of view to fix the attention on the fact that the altitude of multi-storey buildings is the last thing associated with the perception of "high".

It would be reasonable to understand that the term "high" means, first of all, a "high level" associated with quality... "high" meaning "elevated"; however, there are also high 
pitch (of voice), high pain threshold and many other derivatives from the notion, including: higher education, elevated temper, and, surely, high-tech, etc.

The notion of "the New" as a strive for perfection in this atmosphere of diversified understanding what is "high", as applicable to high-rise buildings, provides for considerable extension of the meaningful creative attitude to fully perceived 3-dimensional urban structure.

It is worth noting at this point that this issue is interesting to the author of the article as a process, in dynamics (evolution) of the notions which "do not stand still" but improve their performance. Thus, it is difficult today to speak on a 3-dimensional arrangement of urban space without taking into account the notion of "3D language space" [3]. The understanding of the subjects embraced by grammatology, syntax and other liberal science disciplines gives the opportunity for better correlation of general and specific in the course of Russian and foreign experience comparison than the "direct" comparative analysis of high-rise construction. In this context, the widely discussed modern architecture of skyscrapers in different countries based on the morphology lying on (ascending to) V.G. Shukhov's patents of 1896, acquires, inter alia, a deeper meaning. The patents provided for one of the main trends lasting over a century [4]. (It would be proper to remember that Gothic cathedrals erection based on concepts shaped as projects lasted even longer - at least for 150 years).

\section{Methods}

The magnitude of contemporary is, perhaps the most sensitively and speculatively perceived phrase in the every-day life of all decades that have passed since the beginning of the 20th century. And this is not a surprise: The last century faced so many "tectonic shifts" and revolutionary transformations in Russian history (and architecture was not an exception) that no immediate evaluations (or priorities, to be more exact) can obscure real values which make it into history. It is especially painful for architecture and urban planning, and cannot but be harmful for the comprehension thereof. Permanent changes to creative direction which often do not result from the logics shaping professional trends but are rather susceptible to various passing mindsets, however, break "the life and fate" not only of masters in architecture but also of cities and towns. As the result, they do not allow to bring together the fully functional ideas of coherence, magnitude, regularities of shaping transformations, while the contemporary architecture as a consistent stage of the architectural profession's merging into the future, as a meaningful "morphological carcass" for futurologist concepts, is impossible without them.

In view of such attitude to the discussion of the issue of place and role of Russian highrise construction experience as a fully implemented dialogue between artistic image and intellectual idea as perceived from architectonic point of view of architectural shaping, the previous years, or, to be more exact, 2014-2017, will make it into the history of contemporary architecture as "a break-through". The rules of the "flying geese" game have been overcome. Russian architecture came up to the level of common creative work with its foreign counterparts.

As it should be, the process started somewhat earlier: In 2013, the house in the Mosfilmovskaya Street by S.A. Skuratov was marked with the prestigious international prize Emporis Skyscraper Award. Skuratov was awarded the fifth prize. The third prize was awarded to Jean Nouvele for the skyscraper in Doha (Qatar) [5]. In autumn 2016, Skuratov's Architectural Bureau promulgated the concept of a new quarter of skyscrapers in the Kransnopresnenskaya Embankment, in the immediate vicinity of the Moscow City [6]. The expert community appreciated the deep, comprehensive proposal, and its perhaps 
main advantage - its prospects and promises. The logic of Moscow City creation is developed reasonably and consistently.

But the main subject of our discussion will be the other key urban-planning space of the modern Moscow. I mean the territory of the former automotive plant ZIL (Likhachev Plant). The urban and architectural concept of its renovation was created by Yu.E. Grigoryan's Architectural Bureau Meganom Project. The concept was announced in December 2014. The active design works started in the municipal territory divided into construction lots. Two of them, the key to the perception of the "ZILART Peninsula", are designed by S.A. Skuratov's bureau. The housing complexes within the project do not rush upward. However, there would be a skyscraper in this, practically, new city center. It is being designed by the bureau Asymptote of the architect Hani Rashid [7]. We do not need a detailed analysis of the skyscraper's structure here. It is only notable that the author, in the course of its architectural solution presentation, emphasized that such masters of the 1920ies culture as Dziga Vertov, El Lisitskiy, Gustavs Klucis, would like his concept. This remark by Hani Rashid is the result of the naturally perceived desire to root his work as much as possible in the culture of the place where it is erected. It is to the point to remind that P. Eisenman invited in 2010 to ARCH Moscow Festival, when asked from whom he studied architecture, named J. Derrida and T. Adorno. Derrida came to Moscow in 1990. In numerous lectures and discussions he demonstrated deep knowledge of the shaping experience of OPOYAZ (Society for Poetic Language Studies) and emphasized its integral and significant role for contemporary philosophy of culture and morphological creativity [8].

It is not necessary to speak in detail on the close connection between Zaha Hadid (and other masters of deconstructivism) and Jaques Derrida, on one part, and her infatuation with Malevich's suprematism, works by Lisitskiy. Zaha Hadid turned to their heritage for the creative driver when devising the concept of her (master) diploma's concept (1977) [9].

Many of similar "strokes" taken from every-day architectural practice form the "architectural fabric" of high professional level, the only possible basis for cooperative creative work of most different architectural schools and experts. The New York architect Hani Rashid erects in Moscow the skyscraper which will be the dominant point of ZILART district, based on the urban-planning idea by Yu. Grigorian. The Moscow architect Yu. Grigoryan and his bureau "Meganom Project" approved the concept of the 305-metre-high skyscraper in Manhattan (262 Fifth Avenue Tower). The skyscraper construction with preservation of the existing 12-storey building as its foundation is one of the numerous creative insights drawing attention to the project. (We may even speak about the attitude to heritage preservation in urban environment trained by the Moscow practice of the authors of the skyscraper implemented in the concept devised for New York).

\section{Results}

This is why I find it important to fix (not only for future history but also for our every-day life) an entirely new phase of professional relations between Russian experts in architecture and their star foreign colleagues. The extreme purpose orientation of objectives emerging in the course of modern skyscrapers development provides for deeper understanding of the fact that the creative heritage from Russian Avant-Garde "holds hard" the most bright and deep masters of architecture and thinkers today, after many decades.

Suprematic Architecture. Commitment to Excellence.

World perception today is more and more often based on non-linear regular trends (which are not evident, i.e. are not on a surface) in world outlook. However, the dialogue of an art image and an intellectual idea focused on acquisition of authentic new things in the course of creative activity. 
This is why the interest to suprematic approach to creative process is growing. K.S. Malevich, being both an artist and an art academician, created suprematism as an intellectual art [10]. Basing on cubism, he set out an author's triplicity of conscious attitude to creative work: to see, to know and to build. However, it is notable that in the beginning of the 1910ies construction was perceived as synonymous to creative work (V.Ya. Brusov) [11]. It made creative process definite and shifted the focus from the visionary perception and superficial style formation to the need to perceive creatively and to go deep into the pattern, the structure of spacial integrity. At the same time, tectology as a general science of organization, or, up to its author, "the humanitarian science of construction" (A.A. Bogdanov) appears [12].

The establishment of suprematic architecture took place in the environment of perception characteristic of that time, as an intentional dialogue of propaedeutics and prolegomena to the notions of "space" and "time". Up to Malevich, suprematism emerges in "the spatial time of the new architectural structuring". In 1928 he wrote in his letter to the editorial board of the journal "Modern Architecture": 'Suprematism appeared in 1913... Form 1918 spatial suprematism, the elements of which appeared in 1915, started its development' ... Therefore, all the way of the new art in all fields of culture came to the modern art, which is architecture" [13].

Unique character of suprematic art is rooted in the perception of its author (founder) K.S. Malevich which developed to become the belief that it is necessary to create a suprematic method - the way of targeted movement towards perfection, constructed as a mental projection from the surface "painted on a canvas" onto the space of the world order.

K. Malevich fixed attention on "all types of culture" jointly making their way to new architecture. Beside his interest to the opportunities of painting without a subject, he went deeply into contemporary scientific advances and engineering developments. However, he was interested not in the specifics of each scientific or engineering disciplines but in the universal character of the world order, its most general regularities, It was natural for Malevich to understand the arrangement of a city, the Universe and a man as the wholesome integral system. Search for interpretation of deep layers on humanitarian and natural-science knowledge with help of images gradually led Malevich to understanding of methodical opportunities of architectonic thinking and activities, as a "pure artistic form". The art, embracing new perception of the world order following the logic of suprematic thinking, advances to understanding of spacial element's role in the structure of contemporary life. Geometric surfaces as suprematic elements interact with the space, organize and customize it. Stylistic regularities go "to the shadow" letting to the foreground the problems of architectural shape creation.

At the same time, the artist El Lisitskiy, in Vitebsk as well, taken away by the charm of Malevich's works, starts to create axonometric suprematic compositions thus translating suprematisn from surface to a space and making a decisive step on the further way to architectons and suprematic architecture itself. Malevich does not simply work on sculptural compositions named "Architecton", he shows at the same time how it can exist in a city [14].

Suprematism managed to lead the architectural Avant Garde, fertilising one of the most significant architectural trends forming the life style of that time - constructivism. Suprematism gave it an additional momentum and professional tools necessary on the way to perfection, search for one's creative maximum (first of all, in the works by L.M. Khidekel from the workshop of A.S. Nikolskiy and I.I. Leonidov, an apprentice of A.A. Vesnin).

Later on, the suprematic architecture was not in demand in Russia for some decades. Scientific interest to it as well as to other Avant Garde culture manifestations showed itself in the 1960ies, and in the 1980ies some major exhibitions and publications provided for 
new discussions of suprematic architecture values. The first full-fledged experience of implementation of suprematic architecture ideas ascending to Malevich in our time was Skolkovo campus in Moscow Region (2006-2010). The architect David Adjaye working in England managed to win the international competition for this project as he combines several meaningful planes in his concept, both properly and successfully [15].

Malevich distinguished two types of architectural activities: "architecture as a problem" and "architecture in life". It will be proper to compare the philosophic foundation of Malevich's artistic and theoretical endeavors with noospheric thinking of V.I. Vernadskiy [16]. However, the artist and the scientist moved not towards each other but along parallel ways in the same direction: towards perfect knowledge, and believed wholeheartedly that the parallel ways of the art and the science would merge.

In 1927 in Berlin, L. Lisitskiy put some efforts in the arrangement of the large personal exhibition of the works by Malevich with a great number of publications about the artist, his lectures and other events accompanying any considerable exhibition. Europe saw the art by Malevich first-hand, and he was introduced everywhere as the architect Kazimir Malevich. The suprematic architecture was successfully actualized.

"Figurines" by El Lisitskiy and the idea of the opera

"Victory over the Sun" in 1923: projection from the plane to the space. 2007.

The concept of the opera "Victory over the Sun" conceived as a futuristic work, turned for the future in 1913, as long as I understand, was devised by M. Matushin and A. Kruchenikh not "from scratch". The mute film shot in 1913 and based on A.S. Pushkin's poem "The Small House in Kolomna" written as long ago as in 1830, might serve as a momentum.

It is well known that the authors team of the opera consisted in 1913 of three participants of the First (National) Congress of Russian Futurists. It is of no importance that all three (K. Malevich worked together with the abovementioned authors) were the only delegates to the Congress and "the founding fathers" of both the movement and the futuristic theatre [17].

The problem of the new future construction in the concept of the opera as a futuristic phenomenon made the emphasis on the notion of "the new", and it was the new of the same scale as the maximum manifestation of creative grandeur. A.S. Pushkin was perceived in the context as the only "measure" of perfection - the benchmark. Or rather the personification of the absolute.

The fact that the idea of the opera direction was revisited in 1923 confirms such interpretation of the role "Victory over the Sun" played in the creative life of its authors. I do not think it was only by coincidence that in 1922 Igor Stravinskiy wrote the comic opera "Mavra" based on the same poem by A.S. Pushkin - "The Small House in Kolomna" [18].

The figurines (stage outfits) for that performance were made by El Lisitskiy. However, the outfits by Lisitskiy were not for actors but for puppets which substituted the actors as per the author's concept. It was a great conception. But it was not destined to be implemented. However, inn 1923 in Berlin Lisitskiy published the book of sketches of the outfits. Who could imagine that this story would so symbolically continued in 80 years...

But first let me say some words about the poem "The Small House in Kolomna". Pushkin wrote it not in his traditional iambic rhythm. It was the first time he used octaves!

It was the presentation of innovation in Pushkin's poem in the logic of his time with active focus on the new in art that served as a powerful provocation for the authors of "Victory over the Sun".

From this point of view, "the sophistry" proposed by Kruchenikh is similar to Eisenstein's methods. Numerous reviews of Dziga Vertov's news reels ("cinema eye") also shot in 1920ies, reported by Hani Rashid, is also rooted there. 
In the modern art museum Danubiana Meulensteen near Bratislava one of the figurines from the sketchbook published in Berlin with the self-explanatory name "Coffinmaker" was translated into space. In the park in front of the museum there is the sculpture authored (in accordance with the museum's curators' concept) by El Lisitskiy: "Victory over the Sun", 1923.

It is not by chance that Hani Rashid has permanent reminiscences on behalf of El Lisitskiy and G.G. Klucis. The artist's creative interests merging into the architectural problems was, in this case as well, associated with his strive for the high art. The contemporary master of architecture working in Moscow took interest in the establishment of the creative method born by its time and aimed at excellence in the city.

\section{Conclusions}

Yu. Grigoryan, along with the urban concept, designs large spaces for ZILART. Residential houses along the designed central prospect are located in place of the blacksmith workshop erected against the project by the Vesnin brothers. The spatial solution of the new complex also refers to the works by the Vesnins: Their project for Narcomtyazhprom (People's Commissariat of Heavy Industry) tender in 1934.

It would be up to the point also to remember the conceptual theoretic heritage of the constructivist leaders inseparable from their design studies. In he same issue of the magazine "Architecture in the USSR" (USSR - the Union of Soviet Socialist Republics) (No. 2 of 1934) that published the Decree of the Council for the Palace of Councils under the Presidium of CEC of the Union of SSR (CEC - the Central Executive Committee) on approval of the architectural project and the authors team for the Palace design including: B.I. Iofan, V.G. Gelfreich and V.A. Shuko, published the large (in volume) and undoubtedly conceptual (as for its content) article by A.A. Vesnin, V.A. Vesnin and M.Ya. Ginzburg "Problems of Soviet Architecture" (under the heading "Creative Platform") [19]. The authors closed the discussion on certain then-relevant issues of architect's creative work with the question about "the adequacy of an architect's creative range". "We (Russia Yu.V.) have become wealthier, we have more opportunities, we can now afford to renunciate ascetism (the reference to artistic opportunities of constructivism in that time's discussions - Yu.V.) and much wider scale. It is quite natural that our palette should become an adequate creative palette. But we should find a real delicacy here. Both economic and artistic delicacy".

The issues raised in that article has were developed in the text by I.I. Leonidov, who took part in the later discussion in the same magazine, also under the heading "Creative Platform", on the subject "Technology - Material - Style". His article's title was "Architect's Palette" ... Leonidov and his senior tutors still heard and supported each other. The article by Leonidov looked like a continuation of the conceptual article by the Vesnins and Ginsburg in the framework of the new discussion.

"Has the contemporary architecture mastered new materials and construction not only in engineering but also in artistic sense? What should be the way of further creative work of the Soviet architecture in mastering new construction techniques?" Those we the questions put by the magazine's editorial board before the prospective participants of the discussion [20].

Let us see how I.I. Leonidov exposed the metaphor "architect's palette" in a rather compact (less than one magazine spread) text.

We cannot but note the form of the text presentation. The author laid it out as arguments - strokes on a palette" of an artist. It (palette) unites and arranges the meanings, while the combination of strokes give the opportunity to "mix" them discovering new shades in the 
essence of the same problem discussed together with other participants of the discussion by I.I. Leonidov.

I.I. Leonidov does not speak about the ways an artist-architect can use the palette but about the ways to create it. And this is. I believe, the key to the never dying interest to Avant Garde heritage after a century.

The first argument presented by the author reads as follows: "one on the essential factors predetermining the style and the general composition of an architectural work is, along with social and household conditions, the technology of construction materials and structures. It is well known that this provision was worded for the first time in all its relevance by our functionalists".

It does not matter that after this I.I. Leonidov had to remark on the "mechanistic" approach to this problem in our country and in the West during the previous decade. The mere fact of the reference to the heritage of functionalism (constructivism) and inevitable continuity in the problem discussion speaks for itself. It sets not only "the starting point" but also a precisely aligned ethical level off common discussion, conscious professional responsibility for one's (recent) past. For the author, it was the conversation about the continuity of the world perception worded by constructivism, the return to recently neglected values in its essence. It sounded especially bright and decisive when voiced out by the architect resuming his active professional life.

The first argument set the tone to the rest of comprehension of the subject under discussion by Leonidov. "An architect should not approach construction technologies only from a merely constructive point of view. He should... Master the opportunities given by construction technologies philosophically. He should create new forms and construction of the given material. It is a basic creative need calling for some courage in the search for new forms".

This argument by I.I. Leonidov is supported by profound experience in both philosophical comprehension and shapes creation in Russian architecture and engineering. Today, 80 years later, the results of those speculations have served as the basis of architectural shapes creation adequate to our time and allowed to say that nowadays architectural shapes creation becomes the result of full-fledged cooperation on a parity basis of Russian and foreign experts in architecture.

\section{References}

1. A. Toffler, The Third Wave: The Glassic Study of Tomorrow, 544 (New York. Bantam Books 1980)

2. A. Toffler, The Third Wave, 784 (Moscow, AST, 2010)

3. Yu. S. Stepanov, In 3D Language Environment Semiotic Problems of Linguistics, Philosophy and Art, 335 (Moscow, Nauka Publ. 1985)

4. Genius of V.G. Shukhov and Contremporary Epoch: International Consgress Materials, 319 (Moscow, Bauman MSTU, 2015)

5. URL:https://www.emporis.com/awards/2012 (last accessed on 17.06.2014)

6. URL:https://naked-science.ru/article/concept/plyus-tri-neboskreba-dlya-moskvy (last accessed on 16.04.2017)

7. URL:http://archi.ru/projects/world/9194/bashnya-na-territorii-byvshego-zavoda-zil-zilgateway-tower (last accessed on 25.04.2016)

8. J. Derrida, Jacques Derrida in Moscow: Deconstruction of the Journey. Translated by M. Ryklin, 198, (Moscow, Ad Marginem, 1993)

9. Zaha Fadid at the Hermitage, 208 (St. Petersburg, Arca, 2015) 
10. Yu. P. Volchok, Suprematic Architecture: Style. Method. Commitment to Excellence Televant Problems of Theory and History of Art. Issue VII, 332-333 (St.Petersburg, Publishing House of St.Petersburg University, 2016)

11. V. Ya. Brusov, Keys to Mysteries, Magazine Vesy 1 (Moscow, Scorpio Publishing House 1904)

12. A. A. Bogdanov, Tectology. Comprehensive Science of Organization, 300 (LeningradMoscow, Kniga Pubishing House 1925)

13. K. S. Malevich, Letter to Editorial Board of Modern Architecture Magazine, Modern Architecture, 5, 156 (1928)

14. S. O. Chan-Magomedov, Idols of Avant, Kazimir Malevich, 217 (Moscow. R.E. Gordeev Publishing House, 2010)

15. URL:http://archi.ru/projects/world/4835/moskovskaya-shkola-upravleniya-skolkovo (last accessed on 25.04.2016)

16. V. I. Vernadskiy, The Biosphere and the Noosphere, (Ayris Press, Moscow, 2013)

17. K. S. Malevich, Articles, Manifests and Other Works, 1913-1929, 5-volume set of works, 395 (Hylaea Publishing House, 1995)

18. A. S. Pushkin, Small House in Kolomna, 10-volume set of works, 3, 539, Poems, Fairy Tales (Moscow, Fine Literature State Publishing House, GIHL 1959-1962)

19. A. A. Vesnin, V. A. Vesnin, M. Ya. Ginzburg, Problems of Soviet Architecture, Magazine Architecture in the USSR, 2, 64-69 (1934)

20. I. I. Leonidov, Architect's Palette, Magazine Architecture in the USSR, 4, 33-34 (1934) 